\title{
PENGEMBANGAN MODEL PEMBELAJARAN PASSING PERMAINAN SEPAK BOLA DI SMP NEGERI 7 WASILEI HALMAHERA TIMUR
}

\author{
Hamid Ngolo ${ }^{1)}$, Mukhlis Nur Abdul Gani Ohoirat ${ }^{2)}$ \\ Pendidikan Olahraga STKIP Kie Raha \\ Email :1hamidngolo@gmail.com \\ ${ }^{2}$ mukhlisnurohoirat@gmail.com
}

\begin{abstract}
ABSTRAK
Tujuan dari penelitian adalah untuk mengembangkan model pembelajaran passing dalam permainan sepakbola pada siswa kelas VIII SMP Negeri 7 Wasilei Kabupaten Halmahera Timur. Berdasarkan hasil wawancara dengan guru penjasorkes 8 Maret 2018 guru mengatakan bahwa siswa saat menerima materi mereka tidak serius, apa yang dijelaskan oleh guru penjasorkes tidak diperhatikan oleh siswa dan mereka selalu bermain. Guru penjasorkes setuju jika saya membuat/mengembangkan model pembelajaran passing di kelas VIII SMP Negeri 7 Wasilei. Kabupaten Halmahera Timur. Penelitian dilakukan SMP Negeri 7 Wasilei. Kabupaten Halmahera Timur. Tinjauan para ahli terdiri 2 orang ahli yaitu ahli pelatih sepakbola, ahli guru penjasorkes. dan subjek uji coba terdiri dari: (1) uji coba kelompok kecil mengunakan 8 orang siswa, dan (2) uji coba kelompok besar atau uji coba lapangan yang terdiri dari 10 orang siswa (sisa dari itu uji coba kelompok kecil). Hasil penelitian berdasarkan evaluasi ahli pelatih sepakbola diketahui rata-rata persentasi adalah $85,68 \%$, dan evaluasi ahli guru penjasorkes di ketahui rata-rata persentasi 90,25\% sehinga model ini dapat digunakan. Data hasil keseluruhan uji coba kelompok besar 100\%. Dan uji coba kelompok kecil $100 \%$. Sehinga model pembelajaran passing dalam permainan sepakbola di SMP Negeri 7 Wasilei Kabupaten Halmahera Timur dapat digunakan.
\end{abstract}

Kata kunci: model pembelajaran, passing, sepakbola.

\section{ABSTRACT}

The purpose of the study was to develop a model of passing learning in football games for eighth grade students of Wasilei 7 Middle School, East Halmahera Regency. Based on the results of interviews with the physical education teacher on March 8, 2018 the teacher said that when students received their material they were not serious, what was explained by the physical education teacher was not noticed by the students and they always played. The physical education teacher agrees if I make I develop a passing learning model in class VIII of SMP Negeri 7 Wasilei. East Halmahera Regency. The study was conducted at SMP Negeri 7 Wasilei. East Halmahera Regency. The review of the experts consists of 2 experts namely expert football coaches, expert physical education teachers. and the trial subjects consisted of: (1) small group trials using 8 students, and (2) large group trials or field trials consisting of 10 students (the rest of the small group trials). The results of the research based on the expert evaluation of the soccer coach found that the average percentage was $85.68 \%$, and the expert evaluation of the teacher training was known as an average percentage of $90.25 \%$ so that this model could be used. The overall results of the $100 \%$ large group trial data. And $100 \%$ small group trials. So that the model of passing learning in soccer games at Wasilei 7 Public Middle School, East Halmahera District can be used.

Keywords: Learning Model, Passing, Football. 
http://ejurnal.budiutomomalang.ac.id/index.php/ipjok

Jp.jok (Jurnal Pendidikan. Jasmani , Olahraga dan Kesehatan)
Volume 2, Nomor 1, Nov 2018

P-ISSN 2613-9421

E-ISSN 2654-8003

\section{PENDAHULUAN}

Pendidikan jasmani dan kesehatan merupakan salah satu upaya untuk mengoptimalkan kemampuan belajar.Pengembangan model pembelajaran pendidikan jasmani olahraga dan kesehatan merupakan salah satu upaya yang dapat dilakukan untuk membantu penyelesaian masalah sulitnya siswa untuk aktif bergerak, Pengembangan model pembelajaran pendidikan jasmani olahraga dan kesehatan yang dilakukan oleh para guru dapat membawa suasana pembelajaran yang baru, lebih inovatif, dengan terciptanya pembelajaran yang menyenangkan dan memotivasi siswa, (Britydkk, 2015). Salah satu kurikulum yang terdapat khususnya pada pendidikan formal adalah pendidikan jasmani. Menurut (Rusli Lutan, 2002), pendidikan jasmani itu tak lain adalah "proses belajar untuk bergerak, dan belajar melalui gerak"1. Tujuan belajar pendidikan jasmani mengacu pada perubahan prilaku peserta didik yang bisa terarah baik secara jasmani dan rohani.

Sedangkan menurut (Dini Rosdiani, 2012) menyatakan "pendidikan jasmani adalah proses pendidikan yang memanfaatkan aktivitas jasmani yang direncanakan secara sistematik bertujuan untuk mengembangkan dan meningkatkan individu secara organik, neuromuskuler, perseptual, kognitif dan emosional, dalam kerangka sistem pendidikan nasional"2. Tujuan dari pendidikan jasmani dilembaga-lembaga pendidikan diantaranya adalah untuk meningkatkan kemampuan siswa melalui aktivitas jasmani yang diaplikasian pada cabang-cabang olahraga yang sudah memasyarakat di lingkungan suatu lembaga pendidikan atau sekolah bersangkutan. Salah satu materi dalam pendidikan jasmani adalah sepak bola.

Sepak bola juga merupakan cabang olahraga yang banyak digemari oleh seluruh lapisan masyarakat, baik tua maupun muda, (Rustam E, 201). Permainan sepakbola merupakan salah satu cabang olahraga yang sangat populer didunia, dengan jumlah yang dimainkan oleh 11 orang dengan tujuan mencetak gol kegawang lawan, setiap pemain memiliki tugas dan peran yang sama yaitu harus mampu menyerang dan bertahan dengan baik (Martha dkk, 2017).Menurut (Wildan Herdiansyah, 2011), keterampilan yang paling utama adalah menguasai teknik-teknik dasar sepakbola. Teknik tersebut, seperti mengumpan dan menerima (passing and receving), menembak (shooting), mengontrol bola dengan berbagai anggota badan, melindungi bola dan menggiring bola (dribbiling). Ketiga kita mebutuhkan kerja sama (teamwork). Sedangkan menurut (Yasruddin, 2012) teknik dasar bermain sepakbola antara lain menendang (kicking), menghentikan bola (stopping/control), menggiring (dribling), menyundul bola (heading), teknik melempar bola (throwin), mengumpan (passing), dan teknik menangkap bola (bagi penjaga gawang). 
http://ejurnal.budiutomomalang.ac.id/index.php/jpjok

Jp.jok (Jurnal Pendidikan. Jasmani , Olahraga dan Kesehatan)
Volume 2, Nomor 1, Nov 2018

P-ISSN 2613-9421

E-ISSN 2654-8003

Passing merupakan salah satu cara memberikan/mengoper bola kepada teman satu tim dengan kaki bagian luar, pungung kaki, dan bisa juga dengan kaki bagian dalam operan ini banyak sekali dimanfaatkan oleh para pemain apa lagi dengan seorang pemain penyerang atau bisa juga pemain galandang penyerang. Olehnya untuk itu passing yang baik sangat dibutukan oleh para pemain karena dengan menguasai tehnik ini akan mempermudah pemain depan atau straiker untuk mencetak gol di gawang lawan (Sucipto, 2000). Ketepatan/ accuracy dalam menendang tidak hanya digunakan untuk passing kepada rekan satu tim saja, ketepatan menendang juga dapat digunakan untuk mencetak gol ke gawang lawan, ( Khoiril, 2013).

Hasil wawancara dengan guru penjas pada tanggal 8 Maret 2018. Guru tersebut mengatakan bahwa siswa kelas VIII telah menerima materi sepak bola terutama passing namun pada saat menerima materi mereka tidak serius, apa yang dijelaskan oleh guru penjas tidak diperhatikan oleh siswa dan mereka selalu bermain. Guru penjas setujuh jika saya membuat/mengembangkan model pembelajaran passing di kelas VIII sekolah SMP Negeri 7 Halmahera Timur. Beliau merespon sekali saya mengembangkan model pembelajaran passing terutama kepada siswa supaya siswa lebih menambah pengetahuan sepak bola terutama tehnik dasar passing. Bukan hanya guru penjas namun guru IPA yang merupakan pendamping tim sepak bola jika ada turnamen di desa Sondo-Sondo, beliau sangat setujuh dan merespon baik karena belum ada model pembelajaran passing dalam materi sepak bola terutama kepada dirinya sendiri Penelitian ini bertujuan untuk mengembangkan model pembelajaran passing dalam sepak bola melalui permainan kecil kepada siswa kelas VIII SMP Negeri 7 Halmahera Timur.

Pembelajaran yang baik adalah pembelajaran yang mampu menciptakan situasi belajar aktif sepanjang masa, Irwansyah, (2018: 47) ${ }^{6}$.Model dapat mendemonstrasikan suatu cara berpikir kepada orang lain dengan memberikan contoh. Secara umum model pembelajaran dapat diartikan sebagai suatu pola atau bentuk pembelajaran yang di dalamnya terdapat langkah-langkah pembelajaran untuk mempelajari suatu topik tertentu sesuai dengan tujuan belajar yang hendak dicapai. Selain itu juga terdapat lingkungan belajar yang dibutuhkan agar pembelajaran tersebut dapat berhasil.

\section{METODE}

Penelitian pengembangan ini, peneliti mengacu model pengembangan (research and development) Brog dan Gall dalam (Winarno, 2011), yang telah dimodifikasi oleh peneliti yakni:(1) Need assessment. Melakukan penelitian yang merupakan analisis kebutuhan (need assessment), melalui 
$\underline{\text { http://ejurnal.budiutomomalang.ac.id/index.php/ipjok }}$

Jp.jok (Jurnal Pendidikan. Jasmani , Olahraga dan Kesehatan)
Volume 2, Nomor 1, Nov 2018

P-ISSN 2613-9421

E-ISSN 2654-8003

wawancara dengan guru mata pelajaran penjas (2) Planning. Melakukan perencanaan pembuatan produk sesuai dengan langkah kedua Borg dan Gall yang dikutip Winarno; (3) Pengembangan produk serta pengevaluasian terhadap para ahli yang sesuai dengan langkah ketiga Borg dan Gall yang dikutip Winarno. (4) Produk awal yang sudah terbentuk dijustifikasi oleh 1 orang ahli sepak bola dan 1 orang ahli pembelajaran; (5) Langkah selanjutnya, produk yang telah dijustifikasi oleh para ahli diuji cobakan di Siswa Kelas VIII SMP Negeri 7 Wasilei Halmahera Timur dengan melibatkan 8 subyek uji coba sesuai dengan langkah keempat Borg dan Gall yang dikutip Winarno. (6) Merevisi hasil uji coba dan memperbaiki atau menyempurnakan hasil uji coba sesuai dengan hasil dari uji coba tahap I (kelompok kecil) sesuai dengan langkah kelima Borg dan Gall yang dikutip Winarno. (7) Uji coba produk akhir atau uji coba kelompok besar dilakukan di Siswa Kelas VIII SMP Negeri 7 Wasilei Halmahera Timur 10 subyek uji coba; (8) Penyempurnaan produk hasil uji coba lapangan berdasarkan hasil dari uji coba lapangan sesuai dengan langkah ketujuh Borg dan Gall.

\section{Uji Coba Produk}

Uji coba produk ini disamping untuk mendapatkan saran dari ahli demi perbaikan atau kesempurnaan produk yang akan dibuat, juga untuk mengetahui apakah dengan produk yang telah dikembangkan layak diajarkan pada siswa kelas VIII SMP Negeri 7 Halamahera Timur.

\section{Desain Uji Coba}

Desain uji coba dilakukan melalui 3 tahap, yaitu evaluasi ahli, uji coba (kelompok kecil) dan uji lapangan (kelompok besar)

\section{a. Evaluasi Ahli}

Untuk memperoleh masukan tentang rancangan produk pengembangan model pembelajaran passing dalam permainan sepak bola, maka produk yang dikembangakan ini terlebih dahulu diuji oleh 2 ahli sepak bola dan 1 guru penjas.

\section{b. Uji Coba (Kelompok Kecil)}

Uji coba kelompok kecil dilaksanakan di SMP Negeri 7 Halamahera Timur dengan subyek 8 siswa. Metode pengambilan subyek yaitu menggunakan prosedur yang dilakukan dalam uji coba ini adalah (1) produk model pembelajaran passing dalam permainan sepak bola kepada siswa, (2) meminta kepada siswa untuk memberikan tanggapan tentang produk model pembelajaran passing dalam permainan sepak bola dengan menggunakan kuesioner. Hasil data yang diperoleh dari uji coba di analisis dan digunakan untuk penyempurnaan produk model pembelajaran passing dalam permainan sepak bola. 


\section{c. Uji Lapangan (Kelompok Besar)}

Uji coba kelompok besar dilaksanakan di SMP Negeri 7 Halamahera Timur dengan subyek 10 siswa. Prosedur yang dilakukan dalam uji coba ini adalah (1) produk model pembelajaran passing dalam permainan sepak bola kepada siswa, (2) meminta kepada siswa untuk memberikan tanggapan tentang produk model pembelajaran passing dalam permainan sepakbola dengan menggunakan kuesioner. Hasil data yang diperoleh dari uji coba di analisis dan digunakan untuk penyempurnaan produk model pembelajaran passing dalam permainan sepak bola di SMP Negeri 7 Halmahera Timur.

\section{Subyek}

Subyek uji coba pengembangan ini adalah;

a. Subyek penilitian awal analisis kebutuhan berupa satu guru penjas dan sebanyak 18 siswa yang mengikuti penelitian di SMP Negeri 7 Halamahera Timur.

b. Subyek uji coba (kelompok kecil), adalah peserta didik siswa kelas VIII SMP Negeri 7 Halamahera Timur dan guru penjas sebanyak 8 orang.

c. Subyek uji (kelompok besar) adalah peserta didik siswa kelas VIII SMP Negeri 7 Halamahera Timur yang mengikuti 10 peserta didik sisa dari itu uji coba tahap 1.

d. Subyek evaluasi terdiri dari 1 orang ahli sepak bola, coach byangkara tiga raksa foot ball school (tangerang).

\section{Jenis Data}

Jenis data yang didapat ada dua macam, yaitu data deskriptif dan pengambilan diperoleh dari pengambilan data melalui penelitian awal, berupa analisis kebutuhan yang diberikan kepada satu guru penjas dan kepada 18 peserta didik kelas VIII SMP Negeri 7 Halmahera Timur. Sedangkan disebut data kualitatif di peroleh dari observasi terhadap penilaian peserta didik dan guru penjas terhadap produk yang telah di buat yang berjudul pengembangan model pembelajaran passing dalam permaiana sepak bola serta tinjauan para ahli

\section{Instrumen Pengumpul Data}

Instrumen yang digunakan dalam pengembangan model pembelajaran passing dalam permainan sepak bola adalah dengan menggunakan kuesioner untuk analisis kebutuhan, ahli guru penjas, uji coba (kelompok kecil) dan uji lapangan (kelompok besar). Bentuk angket untuk uji coba serta uji lapangan berbeda.

Kuesioner/ angket ini digunakan untuk mengumpulkan data tentang:

a. Analisis kebutuhan

b. Evaluasi dari ahli, penilaian tentang rancangan produk yang akan dibuat. 
c. Penilaian/tanggapan siswa SMP Negeri 7 Halamahera Timur. tentang model pembelajaran passing dalam permainan sepak bola yang telah dibuat.

\section{Teknik Analisis Data}

Teknik analisis data yang digunakan dalam pengembangan model pembelajaran passing dalam permainan sepak bola untuk SMP Negeri 7 Halmahera Timur. Serta evaluasi dari para ahli untuk uji produk adalah teknik analisis kualitatif dan deskriptif berupa persentase:

Untuk mengolah data teknik analisis data yang digunakan adalah teknik analisis kualitatif dan deskriptif berupa persentase:

a. Analisis kualitatif digunakan untuk menganalisis hasil pengumpulan data dari tinjauan para ahli menggunakan pendekatan kualitatif. Data kualitatif dianalisis menggunakan model Miles dan Huberman (Sugiyono, 2008) yang terdiri dari tiga langkah, yaitu: “(1) Data reduction (2) Data display (3) Conclusion drawing"

b. Analisis deskriptif yang berupa persentase digunakan untuk menganalisis hasil pengumpulan data ujicoba kelompok kecil dan ujicoba kelompok besar. Rumus untuk mengolah data yang berupa deskriptif persentase, (Sudijono,2008) adalah sebagai berikut:

$$
P=\frac{F}{N} \quad \begin{array}{ll}
\text { X } \\
\end{array}
$$

Keterangan :

$f$ : Frekuensi yang sedang dicari persentasenya

$\mathrm{N}$ :Number of case (jumlah frekuensi dari banyaknya individu)

$\mathrm{P}$ :Angka persentase

Menurut pendapat yang disampaikan (Arikunto,2006). “Apabila datanya berupa persentase, proporsi maupun rasio, maka kesimpulan dapat diambil, disesuaikan dengan permasalahannya". Berikut ini penggolongan persentase kategori yang akan digunakan adalah:

$\begin{array}{lll}76 \%-100 \% & \text { Kategoribaik } & \text { digunakan } \\ 56 \%-75 \% & \text { Kategoricukup } & \text { digunakan } \\ 40 \%-55 \% & \text { Kategorikurangbaik } & \text { tidakdigunakan } \\ <40 \% & \text { Kategoritidakbaik } & \text { tidakdigunakan }\end{array}$

\section{HASIL DAN PEMBAHASAN} Analisis Data Ahli Pelatih Sepak Bola

Berikut ini adalah analisis data yang dilakukan berdasarkan data hasil evaluasi ahli pelati sepakbola, masing-masing di deskripsikan pada tabel 4.6 berikut ini: 
Tabel 1. Analisis Data Ahli Pelatih Sepak Bola

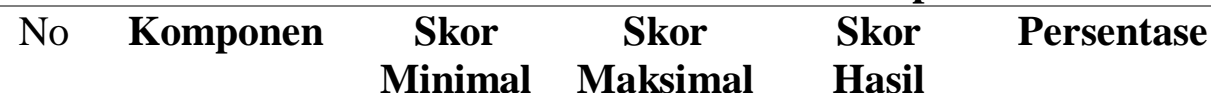

\begin{tabular}{cccccc}
\hline 1. & Model 1 & 4 & 16 & 14 & $87 \%$ \\
\hline 2. & Model 2 & 4 & 16 & 14 & $87 \%$ \\
\hline 3. & Model 3 & 4 & 16 & 15 & $93,75 \%$ \\
\hline 4. & Model 4 & 4 & 16 & 12 & $75 \%$ \\
\hline \multicolumn{5}{c}{ Rata-rata persentasi }
\end{tabular}

Berdasarkan tabel data hasil evaluasi dari ahli pelatih sepak boladapat disimpulkan bahwa secara keseluruhan diperoleh persentase 85,68\% sehingga pengembangan model pembelajaran passing dalam permainan sepakbola.

Hasil evaluasi ahli pelatih sepak bola dapat perolehan hasil yang dapat diilustrasikan dalam bentuk diagram batang seperti pada gambar 1 dibawah ini:

\section{HASIL EVALUASI AHLI}

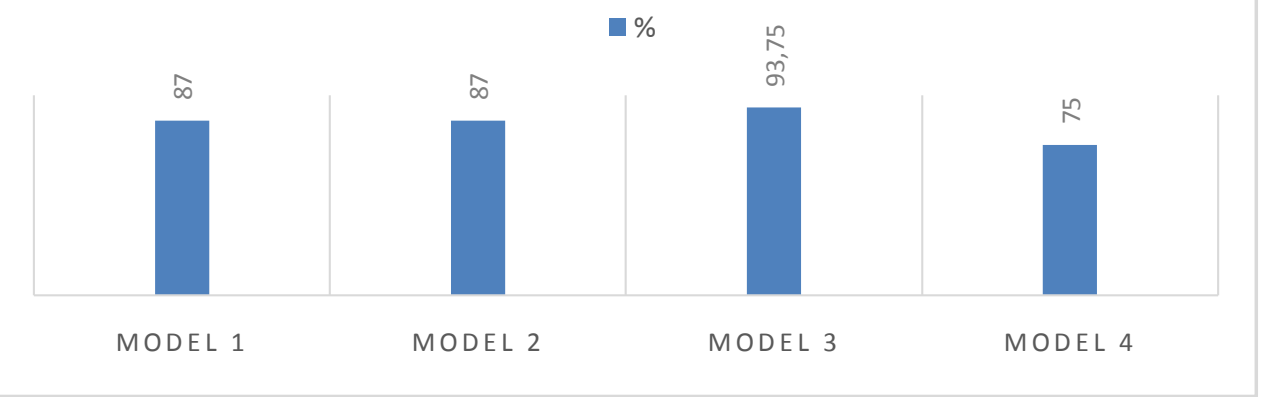

Diagram 1. Hasil Evaluasi Para Ahli

\section{Analisis Data Ahli Guru Penjasorkes.}

Berikut ini pada tabel berikut ini adalah analisis data yang dilakukan berdasarkan data hasil evaluasi ahli guru penjasorkes, masing-masing dideskripsikan berikut ini.

Tabel 2. Data Hasil Evaluasi Guru penjasorkes

\begin{tabular}{llllll}
\hline No & Komponen & $\begin{array}{c}\text { Skor } \\
\text { Minimal }\end{array}$ & $\begin{array}{c}\text { Skor } \\
\text { Maksimal }\end{array}$ & $\begin{array}{c}\text { Skor } \\
\text { Hasil }\end{array}$ & Persentase \\
\hline 1. & Model I & 4 & 16 & 16 & $100 \%$ \\
\hline 2. & Model II & 4 & 16 & 14 & $89 \%$ \\
\hline 3. & Model III & 4 & 16 & 14 & $87 \%$ \\
\hline 4. & Model IV & 4 & 16 & 14 & $87 \%$ \\
\hline \multicolumn{2}{l}{ Rata-rata Persentase } & & & $\mathbf{9 0 , 2 5 \%}$ \\
\hline
\end{tabular}

Hamid Ngolo. Pengembangan Model Pembelajaran Passing Permainan Sepak Bola Di Smp Negeri 7 Wasilei Halmahera Timur 
Berdasarkan tabel data hasil evaluasi dari ahli media dapat disimpulkan bahwa secara keseluruhan diperoleh persentase 90,25\% sehingga pengembangan model pembelajaran passing dalam permainaan sepakbola pada siswa kelas VIII SMP Negeri 7 Wasilei.

Hasil evaluasi ahli media dapat perolehan hasil yang dapat diilustrasikan dalam bentuk diagram batang seperti pada gambar 2 dibawah ini:

\section{HASIL EVALUASI AHLI}

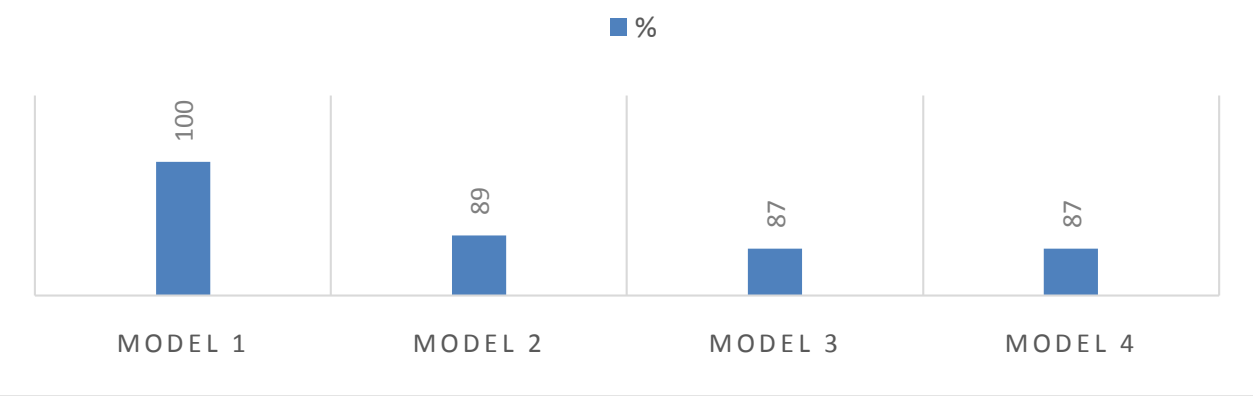

Diagram 2. Hasil Evaluasi media

\section{Analisis Data Uji Coba Tahap I (Kelompok Kecil)}

Berikut ini adalah analisis data yang dilakukan berdasarkan data hasil uji coba tahap I (kelompok kecil), masing-masing dideskripsikan pada tabel 4.8 berikut ini:

\section{Tabel 3. Data Hasil Uji Coba Tahap I (Kelompok Kecil)}

\begin{tabular}{ccccccc}
\hline No & Komponen & $\begin{array}{c}\text { Jumlah } \\
\text { pertanyaan }\end{array}$ & $\begin{array}{c}\text { Skor } \\
\text { Minimal }\end{array}$ & $\begin{array}{c}\text { Skor } \\
\text { Maksimal }\end{array}$ & $\begin{array}{c}\text { Skor } \\
\text { Hasil }\end{array}$ & Persentase \\
\hline 1. & Model I & 3 & 3 & 12 & 12 & $100 \%$ \\
\hline 2. & Model II & 3 & 3 & 12 & 12 & $100 \%$ \\
\hline 3. & Model III & 3 & 3 & 12 & 12 & $100 \%$ \\
\hline 4. & Model IV & 3 & 3 & 12 & 12 & $100 \%$ \\
\hline \multicolumn{7}{r}{} \\
\hline
\end{tabular}

Berdasarkan tabel data hasil uji coba tahap I (kelompok kecil) dapat disimpulkan bahwa secara keseluruhan diperoleh rata-rata persentase $100 \%$ sehingga pengembangan model pembelajaran passing dalam permainan sepakbola.

\section{Analisis Data Uji Coba Tahap II (Kelompok Besar)}

Berikut ini adalah analisis data yang dilakukan berdasarkan data hasil uji coba tahap II (kelompok besar), masing-masing di deskripsikan pada tabel berikut ini: 
Tabel 4. Data Hasil Uji Coba Tahap II (Kelompok Besar)

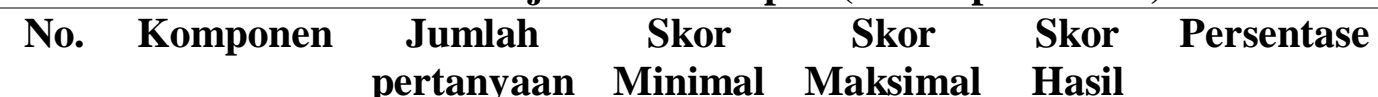

\begin{tabular}{ccccccc}
\hline $\mathbf{1}$ & Model I & 3 & 3 & 12 & 12 & $100 \%$ \\
\hline $\mathbf{2}$ & Model II & 3 & 3 & 12 & 12 & $100 \%$ \\
\hline $\mathbf{3}$ & Model III & 3 & 3 & 12 & 12 & $100 \%$ \\
\hline $\mathbf{4}$ & Model IV & 3 & 3 & 12 & 12 & $100 \%$ \\
\hline & & Rata-rata Persentase & & $\mathbf{1 0 0} \%$ \\
\hline
\end{tabular}

Berdasarkan tabel data hasil uji coba tahap II (kelompok besar) dapat disimpulkan bahwa secara keseluruhan diperoleh rata-rata persentase $100 \%$ sehingga pengembangan model pembelajaran passing dalam permaiana sepakbola.

Berdasarkan rekapitulasi hasil uji coba di perolehan hasil yang dapat diilustrasikan dalam bentuk diagram batang seperti pada gambar 3 dibawah ini:

\section{Revisi Produk}

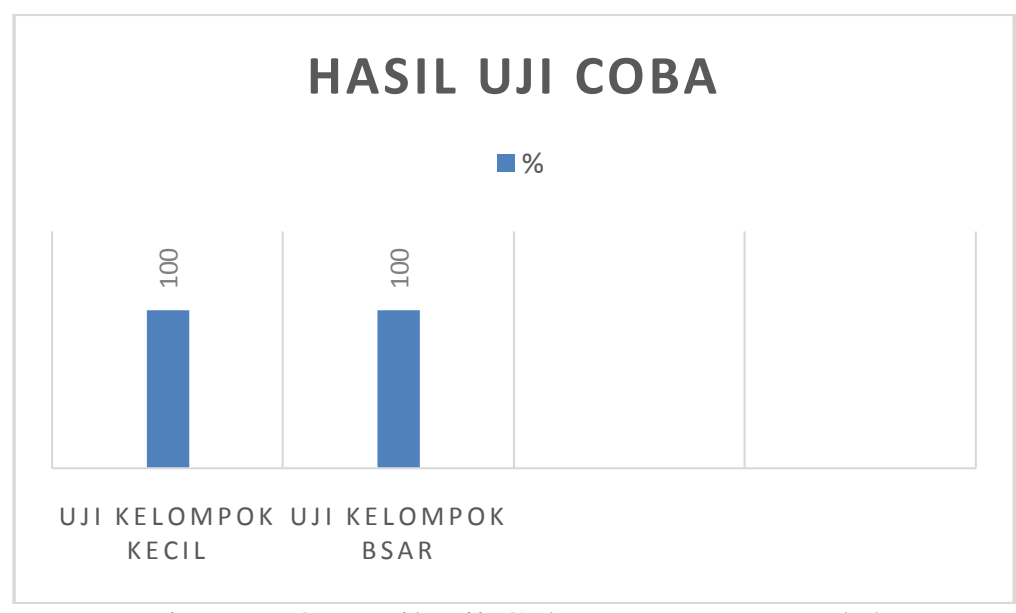

Diagram 3. Hasil Uji Coba Pengguna Produk

Berdasarkan data yang dikumpulkan dari ahli pelatih sepakbola dan ahli guru penjasorkes ada beberapa produk tidak perlu direvisi karna produk yang dikembangkan lebih sempurna dan lebih optimal.

\section{Revisi Produk Oleh Ahli Pelatih Sepak Bola}

Pada tabel akan ditampilkan revisi berdasarkan saran dari ahli pelatih sepakbola sebagai berikut: 
Tabel 5. Data Hasil Revisi Produk Oleh Ahli Pelatih Sepak Bola Hasil Evaluasi Revisi Produk

\section{Ahli Pelatih sepakbola.}

\section{Kondisi awal :}

- 4 model pembelajaran passing untuk peserta didik siswa kelas VIII SMP Negeri 7 Wasilei.

\section{Komentar ahli pelatih sepak} bola:

- Model 1, menarik, lebih menarik lagi dalam satu seson memberikan materi di kasi waktu dalam jangka waktu beberapa menit. Kemudian di tambah lagi tingkat kesulitan dengan menambahkan 1 bola jadi kalau 1 bola sudah lancar bisa tambah 2 bola supaya melatih siswa berpikir.

Hasil penelitian lain yang mendukung hasil penelitian ini seperti yang diteliti oleh (Anwar, dkk. 2015) pembelajaran dribbling, passing sepak bola dengan pendekatan permainan dora (sodor bola) dapat meningkatkan hasil belajar pada siswa kelas VI SD N Palebon 02 tahun 2013, Hasil penelitian yang dilakukan oleh (Agung s, dkk. 2015) pembelajaran passing sepak bola menggunakan pendekatan bermain pemburu binatang mempunyai dampak positif, yaitu dapat meningkakan minat dan motivasi belajar siswa.

\section{SIMPULAN}

Kesimpulan yang diperoleh dalam penelitian pengembangan ini yaitu hasil analisis prosentase yang ditetapkan bahawa jika pencapaian prosentase pada interval $76,-100 \%$ berklasifikasi baik yang berarti pengembangan model pembelajaran passing permainan sepak bola layak digunakan, dengan demikian hasil ujicoba pada uji kelompok besar secara keseluruhan aspek yang dinilai telah mencapai $100 \%$ maka produk pengembangan model pembelajaran passing permainan sepak bola yang telah disusun berklasifikasi baik dan bisa/layak digunakan sebagai bahan pembelajaran pada siswa kelas VIII SMP Negeri 7 Wasilei Kabupaten Halmahera Timur.

Saran yang dapat dijadikan acuan sebagai hasil dari kesimpulan penelitian yang ada adalah siswa diharapkan untuk selalu aktif dan konsentrasi dalam mengikuti proses pembelajaran khususnya materi sepak bola agar isi pembelajaran yang disampaikan dapat diterima dengan baik. 
Diharapkan guru penjas untuk menginovasikan isi pembelajaran yang diberikan dengan mengaplikasikan media pembelajaran yang sesuai agar mengoptimalkan tujuan pembelajaran. Diharapkan sekolah untuk mendukung pemenuhan sarana dan prasarana pembelajaran agar dapat menunjang isi pembelajran yang disampaikan berkaitan dengan pencapaian tujuan belajar.

\section{DAFTAR PUSTAKA}

Arikunto. S. 2006. Prosedur Penelitian Suatu Pendekatan Praktek Edisi Revisi VI. Jakarta: RinekaCipta.

Agung s, dkk. 2015. Peningkatan Hasil Belajar Passing Sepak Bola Melalui Permainan Pemburu Binatang. ACTIVE 4 (10) (2015) Journal of Physical Education, Sport, Health and Recreations. ISSN 2252-6773.

Anwar, dkk. 2015. Peningkatan Pembelajaran Sepak Bola Melalui Modifikasi Permainan Sepak Bola (Dora) Dalam Pembelajaran Penjasorkes Kelas Vi Sd Negeri Palebon 02 Kec. Pedurungan Kota Semarang Tahun 2013. ACTIVE 4 (10) (2015) Journal of Physical Education, Sport, Health and Recreations. ISSN 2252-6773.

Britydkk. 2015. Pengembangan Model Pembelajaran Sepakbola Dengan Permainan "Balangka" DalamPenjasorkesKelas VIII SMP NEGERI 1 Kota Semarang TahunPelajaran 2013/2014. ACTIVE 4 (10) (2015) Journal of Physical Education, Sport, Health and Recreations. ISSN 2252-6773

Dini R. 2012. Model Pembelajaran langsung Dalam Pendidikan Jasmani dan Kesehatan. Bandung: Alfabeta.

Irwansyah. 2018. Pengembangan Buku Ajar Teori Tenis Meja Bagi Mahasiswa Kelas A 2016 Jurusan PJKR IKIP Budi Utomo Malang. Jp.jok (Jurnal Pendidikan. Jasmani, Olahraga dan Kesehatan) Volume 1, Nomor 2, P-ISSN 2613-9421.

Khoiril. 2013. Pengembangan Latihan Ketepatan Tendangan dalam Sepakbola untuk Anak Kelommpok Umur 13-14 Tahun. Jurnal Media Ilmu Keolahragaan Indonesia Volume 3. Nomor 2. Edisi Desember 2013. ISSN: 2088-6802 
Martha dkk, 2017. Analisis Kemampuan Teknik Dasar Bermain Sepakbola Pada Pemain Usia 16 Tahun. Kinestetik: Jurnal Ilmiah Pendidikan Jasmani, 1 (2) ISSN 2477-3311.

Rusli L. 2002. Asas-asas Pendidikan Jasmani Pendekatan Pendidikan Gerak di Sekolah Dasar. Jakarta: Depdiknas.

Rustam E. 2016. Pengaruh Metode Latihan Practice Session, Test Session dan Motivasi Berprestasi Terhadap Keterampilan Menendang dalam Sepak Bola. Jurnal Pendidikan Unsika Volume 4 Nomor 1, Maret 2016 Issn 23382996

Sucipto, dkk. (2000). “Sepakbola”. DepartemenPendidikandanKebudayaan

Sudijono, A. 2008. PengantarStatistikPendidikan. Jakarta: GrafindoPersada.

Sugiyono.2008. MetodePenelitianKuantitatif, Kualtitatifdan $R \quad \& \quad D$. Bandung: Alfabeta.

Wildan H. 2011. Mengenal Sepakbola. Jakarta Timur :WadahIlmu

Winarno. 2011. Metodologi Penelitian Dalam Pendidikan Jasmani. Malang: Media Cakrawala Utama Press.

Yasriuddin. 2012. Survey Keterampilan Bermain Sepakbola Siswa SMA Negeri 3 Sungguminasa Kabupaten Gowa. JurnalILARA, Volume III, Nomor 2, Juli-Desember 2012, hlm. 63 - 71 